\title{
La muerte tuvo permiso. Necrología indispensable de $2015^{1}$ Para los periodistas asesinados en Veracruz \\ Por Celia del Palacio Montiel $^{2}$
}

Cada año, desde 2010, gracias al empeño de la doctora Norma Esther García Meza, se han celebrado en el Centro de Estudios de la Cultura y la Comunicación las Jornadas de Cultura Funeraria. Ha ido pasando el tiempo y éstas se han convertido en parte central de nuestro hacer académico.

2015 no fue la excepción y noviembre llegó una vez más, con su aroma a cempasúchil y velas de miel, con su falda de papel picado y la estela de copal que se confunde con los pétalos de las flores de muerto que muestran el camino de regreso a los difuntos. De nuevo estuvimos presentes en la celebración y al igual que mis compañeros, celebro el privilegio de tener voz para contar y siento más que nunca la obligación de hacerlo. No me resigno, porque hay algo de cobarde en la resignación y el silencio es, además de cobardía, una forma abyecta de complicidad. Por eso, antes de iniciar esta necrología, alzo la voz para evocar a cinco personas, cuyas muertes fueron injustas, incomprensibles, absurdas, como muchas otras.

Pido permiso para iniciar este fúnebre recorrido con los comunicadores asesinados en 2015, para hacerles un lugarcito especial a esos cuyos nombres probablemente han sido ya olvidados, injusta, dolorosamente olvidados, como si no merecieran un lugar en la lista de los hombres y las mujeres célebres que dieron lustre a las artes y a la cultura y que murieron este año. Volveré a estos más tarde.

Apenas iniciaba el año. El 2 de enero nos dieron la noticia. Moisés Sánchez Cerezo fue "extraído de su domicilio" en Medellín -para usar el lenguaje quirúrgico de las agencias oficiales-. 23 días más tarde supimos que se "habían encontrado sus restos" cerca de Soledad de Doblado. El lenguaje puede ser engañoso, tiene una carga ideológica y nosotros lo sabemos bien. Se usan palabras suaves para no herir las susceptibilidades de las gentes bien pensantes en cuyo mundo nunca pasa nada.

Moisés Sánchez, ese periodista ciudadano cuyo oficio le ha sido escatimado, negado, despreciado ("era conductor de taxi y tenía una página

1.- La presente cronología fue posible gracias al trabajo de Hazel Hernández Guerrero, quien documentó los decesos de las figuras de la escena artística y cultural mundial, y a la gentileza de Norma Esther García Meza. Para no entorpecer la lectura y por el gran número de notas periodísticas en las que se fundamenta esta necrología, estas solo se refieren al final, sin llamadas ni pies de página.

2.- Doctora en Historia por la Universidad Nacional Autónoma de México. Miembro del Sistema Nacional de Investigadores nivel II. Coordinadora del Centro de Estudios de la Cultura y la Comunicación de la Universidad Veracruzana, en donde también realiza sus labores de investigación. Su libro más reciente es Pasado y presente. 220 años de prensa veracruzana (2015). 
de Facebook", dicen que dijo el gobernador), fue secuestrado, fue "levantado" (qué gráfico es el término), fue arrancado de su cama, fue torturado, fue degollado, fue arrojado en una bolsa de basura a una cuneta en una carretera secundaria. Al parecer por denunciar las trapacerías del presidente municipal de Medellín, Omar Cruz.

Moisés Sánchez publicaba un semanario, La Unión, donde denunciaba las carencias de la población de Medellín y abusos de sus autoridades. Moisés daba voz a los sin voz en un municipio que, aunque aledaño a Veracruz-Boca del Río, es uno de los más descuidados en lo que a cobertura informativa se refiere. Lo hacía con sus ganancias como taxista. Pero nadie debe levantar la voz porque cualquiera puede matar a un periodista. Las probabilidades de que salga impune son muy altas.

El 14 de abril, Abel Bautista, director y fundador de Radio Spacio 96.1 en Juxtlahuaca, Oaxaca y presidente de la asociación de radios comunitarias "Vara 7", fue asesinado al salir de su trabajo. Las pistas para saber qué fue lo ocurrido son muy débiles: se habla de envidias por su éxito, o de alguna venganza personal.

En Veracruz, solo pasaron cuatro meses tras el asesinato de Moisés. El 4 de mayo nos llegó la noticia de un nuevo crimen contra un comunicador en Veracruz. Se trataba de Armando Saldaña Morales. El locutor de radio de 53 años trabajaba en los programas La Grilla, Punto y Debate de las estaciones Ke-Buena y Radio Max. También había colaborado con otros medios como El Mundo de Córdoba, El Sol de Córdoba y la Crónica de Tierra Blanca.

Se movía en las arenas movedizas de esa zona, una de las más peligrosas de Veracruz. Vivía en Laguna Chica, municipio de Tezonapa, limítrofe a Cosolapa, Oaxaca. Se trata de un pueblo veracruzano al que solo lo separa del estado vecino una calle. Muy conveniente cuando hay que sacarle la vuelta a la responsabilidad.

Armando Saldaña fue torturado, asesinado de cuatro impactos de bala y abandonado a metro y medio de su camioneta entre las comunidades de Morelos y La Aurora, del lado de Oaxaca. No hay información oficial sobre los motivos del crimen. Se dice que dijo algo desagradable de alguna autoridad en su programa. Cualquiera puede matar a un periodista.

El 26 de junio, el director del periódico El Tábano, de Comonfort, Guanajuato, Gerardo Nieto, fue encontrado degollado en su oficina. Las versiones, una vez más, son contradictorias. Las autoridades de aquel estado afirmaron que dicho crimen no podría atribuirse al ejercicio periodístico de Nieto: que estaba en una fiesta y que el ataque se había dado en el contexto de una riña. El infortunado director de El Tábano es el primer 
periodista asesinado en Guanajuato y según se desprende del editorial reproducido por La Jornada, el órgano de prensa abordaba las relaciones de los grupos de poder con el crimen organizado.

Apenas unos días más tarde, el 2 de julio, nos enteramos de dos asesinatos de periodistas. Uno de ellos, Juan Mendoza Delgado en Veracruz y el otro en Oaxaca: Filadelfo Sánchez. Su esposa, Tayda Pavón, denunció su desaparición el día anterior, luego se fue a buscarlo al SEMEFO y ahí lo encontró. Como a menudo ocurre, las versiones son contradictorias y sería muy difícil saber qué fue lo que pasó. Las autoridades hablaron de un atropellamiento. Juan no presentaba impactos de bala, heridas punzocortantes ni huellas de tortura, dijeron. Su cuerpo fue encontrado en la carretera federal Santa Fe-San Julián, dijeron, otra zona oscura, escenario de ajustes de cuentas, cementerio improvisado.

En algunos medios circuló la imagen del periodista (y también conductor de taxi, porque pocos periodistas honestos en Veracruz pueden vivir de su profesión), con los ojos vendados, con claras huellas de tortura, medio desnudo, tirado en la carretera (no se sabe si en la federal Santa Fe-San Julián o en la autopista Veracruz-Xalapa a la altura de San Julián). Se ignora el lugar preciso donde fue atropellado o donde lo arrojaron de un vehículo en movimiento. No se sabe dónde quedó su taxi, el número 1962, en el que había empezado a trabajar. Solo se dice que la última vez que lo vieron fue en la parada del camión en El Tejar.

Juan Mendoza Delgado había sido reportero de la sección policiaca de El Dictamen durante 16 años. Cubría la zona de Veracruz-Boca del Río-Medellín. El 2013, decidió abrir el portal electrónico Escribiendo la verdad, que se orientaba a la información de este último municipio. Omar Cruz, el edil de Medellín, ya para entonces era una fugitivo: "se ha metido en un agujero", dijo el fiscal, y no han podido encontrarlo hasta hoy.

Filadelfo Sánchez Sarmiento era locutor de la estación de radio La Favorita en Oaxaca. Fue acribillado en Miahuatlán de Porfirio Díaz, presuntamente por agredir a su asesino en la radio.

Pero en México, en todo México, cualquiera puede matar a un periodista, por cualquier razón. La prueba es que 30 días después, el 31 de julio, asesinarían a la activista Nadia Vera y al fotoperiodista Rubén Espinosa, junto a otras tres personas (....) en un departamento de la colonia Narvarte en la ciudad de México.

Los dos se habían autoexiliado de Xalapa, después de haber recibido intimidaciones y amenazas. Nadia formó parte de la Asamblea estudiantil de Xalapa y del movimiento \#YoSoy132; estuvo presente en varias marchas y movimientos de protesta y, al ser amenazada, decidió irse. En 
video dejó testimonio de que hacía responsable por su seguridad al gobernador de Veracruz, Javier Duarte de Ochoa.

Rubén había llegado a Xalapa desde 2009. Formó parte del equipo de campaña del mismo gobernador y de la presidenta municipal de Xalapa Elizabeth Morales. Poco después se integró a la revista Proceso y a la agencia Cuartoscuro, para los que cubría la fuente de movimientos sociales. En los últimos años, Rubén tomó una posición muy crítica en contra del gobierno de Veracruz, exigiendo el esclarecimiento de los crímenes contra periodistas. Él fue uno de los principales promotores del cambio de nombre de la Plaza Lerdo, para ser rebautizada Regina Martínez. Él fue uno de los que puso la efímera placa que daría testimonio del cambio de nombre.

El 14 de septiembre de 2013, Rubén, junto a otros fotógrafos, fue agredido y amenazado para que eliminara las fotografías tomadas durante el desalojo violento de maestros en la Plaza, en vísperas del grito de independencia. Pocos meses después, sería acosado por la fotografía que tomó al gobernador Javier Duarte y que aparecería en la edición 1946 de la revista Proceso el 15 de febrero de 2014. Finalmente, el 9 de junio de 2015, optó por exiliarse a la ciudad de México, después de haber recibido amenazas y sufrido intimidaciones. Como para otros periodistas de diversos lugares del país, para Rubén la ciudad de México aparecía como el lugar seguro, el edén donde la muerte no habría de alcanzarlo. No fue así.

Sabemos que no hay lugar seguro. Sabemos que la muerte llega a todas partes. Aún así, ¿cómo no desear que existiera ese refugio para los perseguidos, para los amenazados, para los intimidados? En México en los últimos años, los muertos siempre son los culpables. Los muertos "algo han debido hacer" para merecer la tortura, la muerte violenta o la no muerte de las fosas clandestinas y la desaparición.

Es poco probable, lamentablemente, que alguno de estos casos llegue a resolverse pronto.

Pasemos a rememorar las otras muertes, aquellas que a tiempo o destiempo, pero no como resultado de ataques violentos, se llevaron a las figuras relevantes de la cultura o las artes en 2015 en todo el mundo.

\section{ENERO}

Ninón Sevilla

Moisés Sánchez Cerezo

Julio Scherer

José Luis Moro

Aleph Castañeda 


\section{Estella Newman}

El primero de enero murió de un paro cardiaco a la edad de 93 años, la bailarina, cantante y actriz cubano-mexicana Ninón Sevilla, que fue una de las figuras más relevantes en el "cine de rumberas". El día siguiente, como ya lo mencioné al inicio de este artículo, fue secuestrado y luego privado de la vida el periodista veracruzano Moisés Sánchez Cerezo. Cinco días más tarde, el 7 de enero hubo que lamentar la muerte, a los 88 años, de Julio Scherer García, fundador de Proceso, periodista crítico y figura importantísima del periodismo contemporáneo en México. José Luis Moro, dibujante español avencidado en México y creador de los dibujos animados "La Familia Telerín", dejó de existir a los 88 años el 13 de enero.

Especialmente triste para los músicos veracruzanos fue el deceso de Aleph Castañeda, joven contrabajista que ya tenía una carrera fulgurante en la escena del jazz más allá de las fronteras del estado, el 16 de enero. Diez días después, el 26, falleció Estrella Newman, conocida pintora, escultura y musicóloga mexicana.

\section{FEBRERO}

\section{Lorena Rojas}

Raquel Tibol

Roberto Bañuelas

El 16 de febrero, dejó de existir la actriz y cantante mexicana, después de una larga enfermedad del hígado, a los 44 años. Apenas días después, el 22, una de las críticas de arte más importantes de México, la maestra Raquel Tibol, encontró su fin a los 91 años de edad y el día 27, Roberto Bañuelas, quien en vida había sido uno de los barítonos más importantes de México, murió a los 84 años.

\section{MARZO}
Magda Guzmán
Miguel Donoso Pareja
Herberto Helder
Tomas Tranströmer

Una de las actrices mexicanas más queridas, Magda Guzmán, falleció de causas naturales a los 83 años, el día 12 de marzo. El 16, el escritor ecua- 
toriano exiliado durante algunos años en México, Miguel Donoso Pareja, también dejó de existir a los 83 años. Dejó como herencia una prolífica obra literaria en la cual destaca "Última canción del exiliado" de 1989. Otro escritor, Herberto Helder, poeta portugués nacido en 1931 y reconocido como el poeta más destacado de la segunda mitad del siglo XX, dejó esta vida el 24 de marzo. Le siguió, tres días más tarde, el también poeta Tomas Tranströmer, quien había recibido el premio nobel de literatura en 2011. El sueco tenía 83 años.

\section{ABRIL \\ Manoel de Oliveira \\ Isabel Fraire \\ Nina Companeez \\ Günther Grass \\ Eduardo Galeano \\ Max Rojas \\ Abel Bautista}

Abril, tal vez el mes más cruel, inició el día 3, con el deceso de Manoel Oliveira, el llamado "poeta portugués del séptimo arte", a los 106 años. Le siguió a la eternidad dos días más tarde, el 5, Isabel Fraire, escritora, traductora y crítica mexicana, a los 80 años. Nina Companeez, la directora francesa quien había llevado a la televisión la obra de Marcel Proust, murió a los 77 años el 9 de abril. El día 13, coincidieron en la muerte tres escritores: Günther Grass, el novelista alemán autor de, entre muchas otras, la maravillosa El Tambor de Hojalata; Eduardo Galeano, el uruguayo que sería tan leído, tan amado por los lectores latinoamericanos y que dejaría su obra Mujeres, apenas terminada antes de su muerte; y Max Rojas, poeta mexicano cuyo nombre completo era Juan Máximo Rojas Proenza, autor de varios libros como El turno del aullante, Ser en la sombra y Cuerpos, y que sin embargo se mantuvo fuera de los grupos literarios, pero reconocido por un gran número de lectores.

El día siguiente, 14 de enero, fue asesinado el periodista radiofónico y presidente de la asociación de radios comunitarias, Abel Manuel Bautista Raymundo, en Juxtlahuaca, Oaxaca.

\section{MAYO}

María Elena Velasco, "La India María”

Maya Plisétskaya 
Soledad Cazorla

Armando Saldaña Morales

Ramón Méndez Estrada

Casi todos los mexicanos de más de treinta años conocieron a La India María, personaje creado por María Elena Velasco, la actriz, comediante, cantautora, bailarina, guionista y cineasta que falleció el 1 de mayo, víctima de cáncer de estómago a los 74 años. Un día después, abandonó esta vida, la bailarina clásica Maya Plisétskaya a los 89 años. Aunque no es una figura de las artes o la cultura, quisimos recordar aquí a Soledad Cazorla, jurista española, quien fue fiscal de la sala contra la Violencia sobre la Mujer durante diez años. Esta "defensora absoluta de la igualdad" dejó de existir a los 60 años el 4 de mayo, víctima de un derrame cerebral. El mismo día, el periodista veracruzano Armando Saldaña Morales fue asesinado en Tezonapa. El día 14, encontró la muerte, también a los 61 años, el poeta infrarrealista Ramón Méndez Estrada, originario de Morelia.

\title{
JUNIO
}

\section{Gustavo Sainz}

Gerardo Nieto

El día 26 de junio, dejó de existir el novelista y editor y catedrático Gustavo Sainz, a los 74 años. Fue uno de los representantes más importantes de la llamada "literatura de la onda" y entre sus novelas destacan Gazapo y La Princesa del Palacio de Hierro. Ese mismo día, fue asesinado el periodista Gerardo Nieto en Comonfort, Guanajuato.

\section{JULIO}

\author{
Jacobo Zabudovsky \\ Juan Mendoza Delgado \\ Filadelfo Sánchez Sarmiento \\ Rubén Espinosa Becerril \\ Nadia Vera
}

El mes de julio se ensañó con los periodistas: el inicio y el fin del mes fueron trágicos. En particular el día 2 coincidieron en el paso al más allá, tres de ellos. Jacobo Zabludovsky, llamado por algunos "emblema del periodismo oficialista", en todo caso controvertido, influyente comunicador que sirvió al régimen durante muchas décadas, murió a los 87 años. 
La noticia de su muerte opacó el asesinato de los periodistas "de a pie" Juan Mendoza Delgado en Veracruz y de Filadelfo Sánchez Sarmiento en Miahuatlán, Oaxaca.

El 31 de julio, fueron brutalmente asesinados Rubén Espinosa Becerril y Nadia Vera, en la ciudad de México, junto a otras tres personas: Yesenia Quiroz Alfaro, maquillista, Mile Virginia Martín, modelo colombiana y Alejandra Negrete Valdés, empleada doméstica.

\section{AGOSTO}

\section{Marco Aurelio Carballo \\ Rocío Sagaón \\ Juan Pastor Llaneza}

El escritor y periodista nacido en 1942, Marco Aurelio Carballo, quien fuera Premio Nacional de Periodismo, dejó de existir el día 1 de agosto. Quince días más tarde, le siguió la coreógrafa, actriz y escultora Rocío Sagaón, quien era muy querida en Xalapa, ciudad donde se avecindó y al cabo murió a los 82 años. Sagaón, cuyo verdadero nombre era Rosa María López Bocanegra, incursionó en el cine al lado del Indio Fernández y recibió varios premios por su labor dancística. El 24 de agosto, Julián Pastor Llaneza quien fue director y escritor de teatro cine y televisión, dejó de existir a los 71 años. Como actor, participó en más de cuarenta películas y dirigió también varias telenovelas.

\section{SEPTIEMBRE}

\section{Eraclio Zepeda \\ Carmen Balcells \\ César Tort \\ Hugo Gutiérrez Vega}

Eraclio Zepeda el muy querido escritor chiapaneco, dejó esta vida a los 78 años el día 17 de septiembre. Zepeda, además de escribir cuento y novela, fue un activo promotor cultural y actor de cine. Sus obras Benzulul o Las Grandes Lluvias son tal vez las más conocidas. El 20 de septiembre, falleció la conocida agente literaria Carmen Balcells, símbolo del "boom" latinoamericano. Tenía 85 años. En los días siguientes, nos dejarían César Tort, músico y compositor, el día 23 y el poeta Hugo Gutiérrez Vega, el día 25. El primero de ellos, sentaría las bases para la enseñanza de la música en México, mientras que el segundo es reconocido como un poeta 
y humanista crítico. Tal vez una de las figuras intelectuales más importantes de México en las últimas décadas.

\title{
OCTUBRE
}

\section{Chantal Akerman \\ Henning Mankell \\ Elena Urrutia}

El cinco de octubre la cineasta belga decidió suicidarse en París a los 65 años. Dejó una importante obra en la cual ponía de manifiesto la alienación femenina y la condición judía. El llamado "maestro de la novela negra” Hennig Mankell le siguió dos días después. El sueco fue también activista a favor de diversas causas y sus novelas cuyo personaje central fue el inspector Kurt Wallander vendieron millones de copias. Otra escritora y también activista -ella por los derechos de las mujeres-, murió el 30 de octubre. Se trata de Elena Urrutia, quien también fue catedrática y una de las primeras investigadoras en temas de género.

\section{NOVIEMBRE}

\author{
Raul Rekow \\ René Girard \\ José Ángel Espinoza, "Ferrusquilla" \\ André Glucksmann \\ Allen Toussaint \\ Germán Robles \\ Gloria Contreras \\ Fátima Mernissi
}

Noviembre fue también muy cruel y se llevó a varios talentos de la música, la actuación y las letras. Raul Rekow fue el primero, el día 2. A los 61 años, este percusionista que formó parte del grupo de Carlos Santana en los Estados Unidos, fue a deleitar a los difuntos con su música al más allá. El día 4, René Girard, historiador y filósofo francés quien había sido fundador de la "teoría mimética", abandonó este mundo a los 91 años. Se dice que su obra "se mueve de forma transversal entre la antropología, la filosofía y la literatura". Los títulos de sus obras reflejan sus intereses y son por demás sugerentes. Literatura, mímesis y antropología; Mentira romántica y verdad novelesca, El chivo expiatorio, Shakespeare: los fuegos de la envidia, Veo a Satán caer como el relámpago y La violencia 
y lo sagrado; Clausewitz en los extremos. Politica, guerra y apocalipsis y Geometrías del deseo.

En otro espacio y con una trayectoria e intereses vitales muy distintos, encontramos a José Ángel Espinoza, quien fue mejor conocido como "Ferrusquilla". Este compositor mexicano murió a los 96 años en Mazatlán, en su natal Sinaloa el día 6 de noviembre. Además de haber actuado en varias películas en compañía de muchos actores de fama internacional, se le recuerda por sus canciones como "Échame a mí la culpa" o "La Ley del monte", entre otras.

El filósofo alemán denunciador de los totalitarismos, André Glucksmann pasó a mejor vida el día 9 de noviembre. "Las miserias del mundo" fueron el motor de su acción, como él mismo lo dijera. El día siguiente, 10 de noviembre, falleció el músico de jazz y compositor Allen Toussaint. Tenía 77 años.

Tras unos días de tregua, la muerte regresó el día 21 a llevarse a Germán Robles, conocido actor español avecindado en México, quien interpretara, entre otros muchos personajes, al vampiro en una de las primeras películas de culto sobre el género en México. Durante diez años actuó en la obra La Dama de Negro y en un sinfín de películas, telenovelas y obras de teatro. Cuatro días más tarde, el 25 de noviembre, coincidieron en el viaje a la eternidad Gloria Contreras, bailarina y coreógrafa y la escritora Fátima Mernissi. La primera de ellas, fue la fundadora del taller coreográfico de la UNAM y montó obras para las compañías de danza más importantes del mundo; su obra coreográfica es invaluable. Finalmente, damos por terminada esta necrología con Fátima Mernissi, escritora, socióloga y profesora marroquí a quien se considera pionera del feminismo musulmán. Su obra Sueños en el umbral: memorias de una niña del harem, es probablemente la más conocida en México.

\section{Epílogo al epílogo}

Esta necrología de ninguna manera puede considerarse exhaustiva ni completa, ni siquiera en lo que se refiere a las personalidades de la cultura y las artes. Como cualquier texto, es producto de las filias y fobias de su autora, de sus conocimientos y posibles intereses. Muy probablemente estén ausentes figuras señeras de las que no tuvimos noticia y por el contrario, hayamos abundado en otras que tal vez no tuvieron la importancia suficiente. La muerte nos iguala a todos. Noviembre llegó con su faldón de crepé negro y su aroma a cempasúchil y sin duda nos recuerda que con amores y desamores, todos iremos a encontrarnos en el concierto sin fin de la eternidad. 


\section{Bibliografía}

Animal Político, "Denuncian desaparición de periodista en Veracruz", enero 2015. http://www.animalpolitico.com/2015/o1/reportan-secuestro-de-periodista-en-veracruz/

REDACCIÓN, Aristegui Noticias, 26 de enero de 2015. "Irreconocible, el cuerpo de Moisés Sánchez; "es algo dantesco": procurador de Veracruz" http://aristeguinoticias.com/2601/mexico/irreconocible-el-cuerpo-de-moises-sanchez-es-algo-dantesco-procurador-de-veracruz/

CASTILLO, Gustavo, 7 de enero de 2015, "Falleció el periodista Julio Scherer a los 88 años", La jornada http://www.jornada.unam. $\mathrm{mx} /$ ultimas/2015/01/o7/fallecio-julio-scherer-garcia-a-los-88anos-6338.html

LA JORNADA, 2015, "Falleció Ninón Sevilla, figura icónica del cine de rumberas", en La jornada en línea, o1 de enero, disponible en:http://www.jornada.unam.mx/ultimas/2015/01/o1/muere-la-actriz-cubana-ninon-sevilla-6734.html

PALOMO MIGUEL ÁNGEL, 2015, "Muere el dibujante José Luis Moro, creador de la familia Telerín", en El país, 15 de enero, disponible en: http://cultura.elpais.com/cultura/2015/o1/14/actualidad/1421224694_964544.html

CONACULTA, 16 de enero de 2015, "Fallece el contrabajista veracruzano Aleph Castañeda", http://www.conaculta.gob.mx/detalle-no$\mathrm{ta} /$ ? id $=38247$

CABALLERO, JORGE, 26 de enero de 2015, "Falleció Estrella Newman, testigo de la vida cultural de México", La jornada http://www.jornada.unam.mx/ultimas/2015/o1/26/fallecio-estrella-newman-testigo-de-la-vida-cultural-de-mexico-9728.html

LA JORNADA, 2015, "Falleció Lorena Rojas, actriz y cantante mexicana”, en La jornada en línea, 16 de febrero, disponible en: http:// www.jornada.unam.mx/ultimas/2015/02/16/fallecio-lorena-rojas-actriz-y-cantante-mexicana-1979.html

MACMASTERS MERRY, 2015, "Muere Raquel Tibol, decana de la crítica de arte en México", en La jornada en línea, 22 de febrero, disponible en: http://www.jornada.unam.mx/ultimas/2015/o2/22/ muere-raquel-tibol-decana-de-la-critica-de-arte-en-mexico-2846. html

VARGAS ÁNGEL, 2015 "Fallece barítono Roberto Bañuelas, figura emblemática de la ópera y cultura mexicana, en La jornada en línea, 27 de febrero, disponible en: http://www.jornada.unam.mx/ulti- 
mas/2015/o2/27/fallece-baritono-roberto-banuelas-figura-emblematica-de-la-opera-y-cultura-mexicana-3956.html

CANTÚ MARÍA JOSÉ, 12 de marzo de 2015, "Magda Guzmán se quedó dormida: su nieta”. Milenio, http://www.milenio.com/hey/cine/ Magda_Guzman_nieta_Magda_Karina-Magda_Guzman_dormida-Magda_Karina-Magda_Guzman_o_479952244.html

LA JORNADA EN LÍNEA, 2015, "Fallece el escritor ecuatoriano Miguel Donoso Pareja”, en La jornada en línea, 16 de marzo, disponible en: http://www.jornada.unam.mx/ultimas/2015/o3/16/fallece-el-escritor-ecuatoriano-miguel-donoso-referente-7891.html

LA JORNADA, 2015, "El escritor portugués Herberto Helder muere a los 84 años", en La jornada en línea, 24 de marzo, disponible en: http://www.jornada.unam.mx/ultimas/2015/o3/24/el-escritorportugues-herberto-helder-muere-a-los-84-anos-6745.html

LA JORNADA, 2015, "Fallece el poeta sueco Tomas Tranströmer, Nobel de Literatura 2011", en La Jornada en línea, 27 de marzo, disponible en: http://www.jornada.unam.mx/ultimas/2015/03/27/ fallece-el-poeta-sueco-tomas-transtromer-nobel-de-literatura-2011-4052.html

OLIVARES JUAN JOSÉ, 2015, "Falleció Manoel de Oliveira, el poeta portugués del séptimo arte”, en periódico La jornada, o3 de abril, p.6, disponible en: http://www.jornada.unam.mx/2015/04/o3/ espectaculos/ao6n1esp

DE LA FUENTE VÉRTIZ COLUMBA, 2015, "Fallece la poeta y traductora Isabel Fraire a los 80 años", en Proceso, 05 de abril, disponible en: http://www.proceso.com.mx/?p=400368

IRUYA, 2015, "Fallece Nina Companeez, la directora que llevó a la televisión la obra de Marcel Proust", en IRUYA, 10 de abril, disponible en: http://noticias.iruya.com/a/sociedad/gente/6719-fallece-ninacompaneez-la-directora-que-llevo-a-la-television-la-obra-de-marcel-proust.html

LA JORNADA, 2015, "Muere a los 87 años el escritor alemán Günter Grass", en La jornada en línea, 13 de abril, disponible en: http:// www.jornada.unam.mx/ultimas/2015/04/13/muere-a-los-87anos-el-escritor-aleman-gunter-grass-9934.html

Garfias Montaño Ericka, 20115, "Fallece el escritor uruguayo Eduardo Galeano", en La jornada en línea, 13 de abril, disponible en: http://www.jornada.unam.mx/ultimas/2015/04/13/fallece-el-escritor-uruguayo-eduardo-galeano-por-cancer-9701.html

VARGAS ÁNGEL, 2015, "Fallece el poeta Max Rojas a los 74 años", en La jornada en línea, 24 de abril, disponible en: http://www.jorna- 
da.unam.mx/ultimas/2015/04/24/fallece-el-poeta-max-rojas-alos-74-anos-5123.html

http://es.rsf.org/mexico-asesinan-al-director-de-una-ra-

dio-20-04-2015,47790.html reporteros sin fronteras, 20 de abril de 2015.

EL UNIVERSAL, 2015, "Fallece María Elena Velasco, "La india María”", en El universal, o1 de mayo, disponible en: http://archivo.eluniversal.com.mx/espectaculos/2015/muere-india-maria-1096709. html

SALAS ROGER, 2015, "Muere Maya Plisétskaya, el gran cisne del ballet clásico", en El país, 03 de mayo, disponible en: http://cultura. elpais.com/cultura/2015/05/o2/actualidad/1430591696_856387. html

CRUZ JUAN, 2015, "Soledad Cazorla, "defensora absoluta de la igualdad"”, en El país, o4 de mayo, disponible en: http://politica.elpais. com/politica/2015/o5/o4/actualidad/1430763991_689103.html

"Reportero veracruzano fue asesinado de cuatro balazos" 4 de mayo de 2015. Redacción. E-consulta, Veracruz. http://e-veracruz.mx/ nota/2015-05-04/periodismo/reportero-veracruzano-fue-asesinado-de-cuatro-balazos

LA JORNADA, 2015, "Muere el poeta infrarrealista Ramón Méndez Estrada”, en La jornada en línea, 14 de mayo, disponible en: http:// www.jornada.unam.mx/ultimas/2015/o5/14/muere-el-poeta-infrarrealista-ramon-mendez-estrada-4769.html

RODRÍGUEZ ANA MÓNICA, 2015, "Murió Gustavo Sainz; el amor es la pasión más habladora, decía”, en La jornada en línea, 02 de julio, http://www.jornada.unam.mx/ultimas/2015/o7/o2/fallece-el-escritor-gustavo-sainz-representante-de-la-literatura-de-la-onda-7063.html

Carlos García, La Jornada. "Asesinan a periodista en Comonfort, Guanajuato" http://www.jornada.unam.mx/ultimas/2015/o6/26/asesinan-a-periodista-en-comonfort-guanajuato-2420.html

PROCESO, 2015, "Fallece Jacobo Zabludovsky, emblema del periodismo oficialista", en Proceso, 02 de julio, disponible en: http://www. proceso.com.mx/?p=409420

Silvia Núñez Hernández, "Viuda del periodista Juan Mendoza no está conforme con versión de que fue atropellado" AGN Veracruz, 3 de julio de 2015. http://www.agnveracruz.com.mx/index.php/menuveracruz/item/21007-esposa-de-mendoza-delgado-no-está-conforme-con-la-versión-de-que-fue-atropellado

Jorge Pérez, "crimen de Filadelfo Sánchez por criticar a su posible ase- 
sino". 8 de julio, 2015. Tiempo en Línea. http://www.tiempoenlinea.com.mx/index.php/oaxaca/47137-crimen-de-filadelfo-sanchez-por-criticar-a-su-posible-asesino

TURATI MARCELA, 2015, "Rubén Espinosa, un fotógrafo 'incómodo' para el gobierno de Duarte", en Proceso, 02 de agosto, disponible en: http://www.proceso.com.mx/?p=412068

RAMIREZ MOLINA TANIA, 2015, "La activista Nadia Vera había huido del clima de violencia en Veracruz", en La jornada, 03 de agosto, p.6, disponible en: http://www.jornada.unam.mx/2015/o8/03/ politica/oo3n1pol

P. De Llano y D.M. Pérez. "Asesinado en México un fotoperiodista que había recibido amenazas" 2 de agosto de 2015. http:// internacional.elpais.com/internacional/2015/08/02/actualidad/1438471146_330192.html

Sinembargo.mx "Colombia identifica a su ciudadana asesinada en la Narvarte y exige que el crimen no quede impune", 6 de agosto de 2015. http://www.sinembargo.mx/o6-08-2015/1441533

"Comunidad cultural lamenta muerte de Marco Aurelio Carballo" 3 de agosto de 2015. http://www.eluniversal.com.mx/articulo/cultura/ letras/2015/o8/3/comunidad-cultural-lamenta-muerte-de-marco-aurelio-carballo

GÓMEZ EIRINET, 2015, “Muere a los 82 años la actriz Rocío Sagaón”, en La jornada en línea, 17 de agosto, disponible en: http://www. jornada.unam.mx/ultimas/2015/o8/17/muere-a-los-82-anos-laactriz-rocio-sagaon-4277.html

LA JORNADA, 2015, "Fallece actor y director mexicano Julián Pastor", en La jornada en línea, 25 de agosto, disponible en: http://www. jornada.unam.mx/ultimas/2015/o8/25/fallece-actor-y-director-mexicano-julian-pastor-760o.html

HENRÍQUEZ ELIO, 2015, "Muere el escritor chiapaneco Eraclio Zepeda", en La jornada en línea, 17 de septiembre, disponible en: http://www.jornada.unam.mx/ultimas/2015/o9/17/muere-el-escritor-chiapaneco-eraclio-zepeda-5472.html

LA JORNADA, 2015, "Muere la agente literaria del 'boom' latinoamericano", en La jornada en línea, 21 de septiembre, disponible en: http://www.jornada.unam.mx/ultimas/2015/09/21/muere-la-agente-literaria-del-201cboom-latinoamericano201d-4806. html

LA JORNADA, 2015, "Muere el compositor César Tort, artífice de la enseñanza musical en México", en La jornada en línea, 24 de septiembre, disponible en: http://www.jornada.unam.mx/ulti- 
mas/2015/o9/24/muere-cesar-tort-quien-combatio-el-rezago-musical-en-mexico-3446.html

MACMASTERS MERRY Y VARGAS ÁNGEL, 2015, "Muere el poeta Hugo Gutiérrez Vega”, en La jornada, 26 de septiembre, p.2, disponible en: http://www.jornada.unam.mx/2015/o9/26/cultura/ a02n1cul

VICENTE ÁLEX, 2015, "Muere la cineasta belga Chantal Akerman a los 65 años”, en El país, o6 de octubre, disponible en: http://cultura. elpais.com/cultura/2015/10/o6/actualidad/1444131748_009557. html

LA JORNADA, 2015, "Muere el maestro de la novela negra Henning Mankell" en La jornada en línea, o5 de octubre, disponible en: http://www.jornada.unam.mx/ultimas/2015/10/o5/muere-elmaestro-de-la-novela-negra-henning-mankel-3842.html

MONTAÑO ERICKA Y VARGAS ÁNGEL, 2015, "Murió Elena Urrutia, activista por los derechos de las mujeres", en La jornada en línea, 30 de octubre, http://www.jornada.unam.mx/ultimas/2015/10/30/fallece-la-periodista-y-escritora-elena-urrutia-5918.html

LA JORNADA, 2015, "Muere Raúl Rekow, el percusionista de Santana”, en La jornada en línea, 04 de noviembre, disponible en: http:// www.jornada.unam.mx/ultimas/2015/11/o4/muere-raul-rekow-el-percusionista-de-santana-7494.html

ARROYO FRANCESC, 2015, "René Girard, historiador francés, fundador de la 'teoría mimética" en El país, o5 de noviembre, disponible en: http://cultura.elpais.com/cultura/2015/11/o5/actualidad/1446757298_232498.html

CÁRDENAS VALDEZ JAVIER, 2015, "Muere el compositor Ferrusquilla a los 96 años", en La jornada en línea, o6de noviembre, disponible en: http://www.jornada.unam.mx/ultimas/2015/11/o6/muere-el-compositor-ferrusquilla-a-los-96-anos-7072.html

LA JONADA, 2015, "Muere el filósofo francés André Glucksmann a los 78 años", en La jornada en línea, 10 de noviembre, disponible en: http://www.jornada.unam.mx/ultimas/2015/11/10/muere-el-filosofo-frances-andre-glucksmann-enemigo-del-totalitarismos-3997. html

LA JORNDADA, 2015, "El jazzista de Nueva Orleáns Allen Toussaint muere a los 77 años", en La jornada en línea. 10 de noviembre, disponible en: http://www.jornada.unam.mx/ultimas/2015/11/10/ el-jazzista-de-nueva-orleans-allen-toussaint-muere-a-los-77anos-3659.html 
LA JORNADA, 2015, "Muere el primer actor Germán Robles", en La jornada en línea, 21 de noviembre, disponible en: http://www.jornada.unam.mx/ultimas/2015/11/21/muere-el-primer-actor-german-robles-1307.html

LA JORNADA, 2015, "Fallece la bailarina y coreógrafa Gloria Contreras", en La jornada en línea, 26 de noviembre, disponible en: http://www.jornada.unam.mx/ultimas/2015/11/26/fallece-la-bailarina-y-coreografa-gloria-contreras-7494.html

PEREGIL FRANCISCO, 2015, "Fallece la marroquí Fátima Mernissi, pionera del feminismo musulmán”, en El país, 30 de noviembre, disponible en: http://internacional.elpais.com/internacional/2015/11/30/actualidad/1448887807_680243.html 